\title{
Structure Optimization of Corrugated Aluminium Sheath of XLPE Power Cables for Longitudinal Water Resistance
}

\author{
Lei $\mathrm{LI}^{1, a}$, Hui TANG ${ }^{* 1, b}$, Xuan SHAO ${ }^{2, c}$, Tong WU ${ }^{3, d}$ \\ ${ }^{1}$ School of Material Science and Engineering, University of Science and Technology, \\ Harbin,150040, China \\ ${ }^{2}$ School of Mechanical and Power Engineering, Harbin University of Science and Technology, \\ Harbin, 150080, China \\ ${ }^{3}$ NKT Cables Ltd. Changzhou, China \\ aemail: 1062357164@qq.com, bemail: Tanghui6003@sina.com, cemail: shaoxuan919@sina.com, \\ demail:379190169@qq.com
}

Keywords: power cable; corrugated aluminium sheath; water resistance; XLPE

\begin{abstract}
In this work, in order to solve the problem of longitudinal water resistance for XLPE power cable, nine kinds of corrugated aluminium sheath with different embossing depths and pitchs were pressed by argon arc welding machine. Each sheath was cut into six equal parts to study lateral pressure. After pressure experiment were finished, a group of structural optimization parameters of corrugated aluminium sheath was obtained. The results showed that, maximum value of the yield-point stress was $2.26 \mathrm{KN}$ when embossing depth was $24.2 \mathrm{~mm}$ and pitch was $4.5 \mathrm{~mm}$ in the longanimous pressure range of the aluminium sheaths. Four kinds of XLPE power cable of length than $3 \mathrm{~m}$ meeting process requirement were preparated to longitudinal water resistance experiment. The longitudinal water resistance experiment of the corrugated aluminium sheath was made by setting four different clearances or precision cutting widths based on structural optimization parameters in pressure experiment. The experiment results indicated that the shortest water penetration length was $0.31 \mathrm{~mm}$ when precision cutting width was $244.7 \mathrm{~mm}$ and clearance was $-0.5 \mathrm{~mm}$, which achieved excellent effect.
\end{abstract}

\section{Introduction}

Crosslinked polyethylene (XLPE) power cables are commonly used for directly buried, cable duct, tunnel and overhead, as main laying modes. Too large external force or mechanical stress of overhead will cause the power cable sheath and insulation layer damage or joint damage, so that ambient water molecules or moisture gradually permeates into the interior of the cable longitudinally or radially. And directly buried also results in the cable short or long soaking in the water because of rainwater infiltration. Consequently, the water will gradually penetrate into the interior of the cable. Water treeing of the XLPE power cable is usually caused by two situations in the operating voltage, and permanent electrical tree defects will be generated in water tree tip at a certain length of water tree[1], which leads to serious operation faults of cable line in a relative short time, such as cable insulation breakdown, blackouts[2][3]. Therefore, good water resistance performance of XLPE power cables are urgently required by more and more users to protect security and reliability of power system[4-7]. But how to improve the water resistance performance of XLPE power cable has become the focus of power cable research today[8-10]. In the paper, longitudinal water resistance performance of XLPE power cable was improved, which based on the experimental optimization of XLPE power cable corrugated aluminium sheath structure with the best mechanical properties.

\section{Experimental}

Experimental material used: Aluminium strip(1.85*261), Water blocking $(2 * 60)$, cable core. 
Experimental equipment used: Argon arc welding machine, Graining machine, Reciprocating saw, WDW-20 Pressure machine, Water-tight experiment machine.

Experimental Sample pressed. First, an aluminium tube of $10 \mathrm{~m}$ length was pressed by argon arc welding machine and made a mark at each $1 \mathrm{~m}$ on it. Then, a corrugated aluminum sheaths with nine kinds of pitchs and embossed depths was prepared for the aluminum tube by graining machine to adjust pitchs and embossed depths. Prepared parameters were shown in table 1. The corrugated aluminium sheath was cut into nine parts from each mark by reciprocating saw. The pitchs and embossed depths of each corrugated aluminium sheath which had been prepared were measured. Four places of different lengths were selected in each corrugated aluminium sheath to measure. Embossed depth and pitch of each place were also measured by selecting four points(upper, lower, left and right), average value was taken from sixteen groups of data to ensure parameters accurately. The results were shown in table 2. Fifty-four corrugated aluminum sheaths were obtained by cutting each corrugated aluminum sheath into six equal parts by reciprocating saw to test lateral pressure. Length of a part was measured by meter ruler and data record. After pressure experiment were finished, a set of optimal mechanical property of the corrugated aluminium sheath was selected in order to longitudinal water resistance experiment. results were shown in table 3 .

Table 1 Prepared Parameters for Nine Kinds of the Corrugated Aluminum Sheaths

\begin{tabular}{|c|c|c|c|c|c|c|c|c|c|}
\hline Sample No. & 1 & 2 & 3 & 4 & 5 & 6 & 7 & 8 & 9 \\
\hline Embosseddepth & 30.9 & 30.9 & 30.9 & 24.2 & 24.2 & 24.2 & 20.4 & 20.4 & 20.4 \\
\hline pitch & 3.5 & 4.5 & 5.5 & 3.5 & 4.5 & 5.5 & 3.5 & 4.5 & 5.5 \\
\hline ratio & 0.113 & 0.145 & 0.178 & 0.145 & 0.185 & 0.227 & 0.172 & 0,221 & 0.27 \\
\hline
\end{tabular}

Table 2 Test Data for Nine Kinds of the Corrugated Aluminum Sheaths

\begin{tabular}{|c|c|c|c|c|c|c|}
\hline Sample No. & Test point & upper & lower & left & right & average value \\
\hline \multirow{5}{*}{1} & depth 1 & 4.1 & 4 & 4 & 4 & 4.0 \\
\hline & depth 2 & 4.3 & 4 & 4.2 & 4.1 & 4.2 \\
\hline & depth 3 & 3.9 & 3.9 & 4 & 3.8 & 3.9 \\
\hline & depth 4 & 4 & 4.2 & 4.3 & 4.3 & 4.2 \\
\hline & pitch & 31 & 30.3 & 32 & 30 & 30.8 \\
\hline \multirow{5}{*}{2} & depth 1 & 4.7 & 4.7 & 4.9 & 4.8 & 4.8 \\
\hline & depth 2 & 4.3 & 4.3 & 4.4 & 4.3 & 4.3 \\
\hline & depth 3 & 4.5 & 4.6 & 4.5 & 4.5 & 4.5 \\
\hline & depth 4 & 4.4 & 4.3 & 4.3 & 4.4 & 4.4 \\
\hline & pitch & 31 & 30.3 & 30.5 & 30.2 & 30.5 \\
\hline \multirow{5}{*}{3} & depth 1 & 5.4 & 5.4 & 5.5 & 5.5 & 5.5 \\
\hline & depth 2 & 6.1 & 5.7 & 5.2 & 5.6 & 5.7 \\
\hline & depth 3 & 5.4 & 5.3 & 5.4 & 5.4 & 5.4 \\
\hline & depth 4 & 5.5 & 5.5 & 5.5 & 5.4 & 5.5 \\
\hline & pitch & 30.3 & 30 & 30.5 & 28.9 & 29.9 \\
\hline \multirow{5}{*}{4} & depth 1 & 3.9 & 3.8 & 4.1 & 3.9 & 3.9 \\
\hline & depth 2 & 3.6 & 3.5 & 4 & 3.7 & 3.7 \\
\hline & depth 3 & 3.7 & 3.7 & 3.7 & 3.6 & 3.7 \\
\hline & depth 4 & 3.7 & 3.7 & 3.9 & 3.7 & 3.8 \\
\hline & pitch & 24 & 24 & 24.3 & 23.3 & 23.9 \\
\hline \multirow{5}{*}{5} & depth 1 & 4.6 & 4.9 & 4.8 & 4.9 & 4.8 \\
\hline & depth 2 & 4.5 & 4.4 & 4.5 & 4.7 & 4.5 \\
\hline & depth 3 & 4.6 & 4.7 & 4.7 & 4.6 & 4.7 \\
\hline & depth 4 & 4.9 & 4.9 & 4.8 & 4.9 & 4.9 \\
\hline & pitch & 24 & 24 & 24.6 & 23 & 23.9 \\
\hline \multirow{2}{*}{6} & depth 1 & 5.7 & 6.8 & 5.6 & 5.6 & 5.9 \\
\hline & depth 2 & 5.1 & 5.4 & 5.4 & 5.3 & 5.3 \\
\hline
\end{tabular}




\begin{tabular}{|c|c|c|c|c|c|c|}
\hline \multirow{5}{*}{} & depth 3 & 5.1 & 5.2 & 5.4 & 5 & 5.2 \\
\cline { 2 - 7 } & depth 4 & 4.9 & 5.4 & 5.3 & 5.1 & 5.2 \\
\cline { 2 - 7 } & pitch & 23.5 & 23.7 & 23.8 & 21.5 & 23.1 \\
\hline \multirow{5}{*}{7} & depth 1 & 3.3 & 3.4 & 3.4 & 3.3 & 3.4 \\
\cline { 2 - 7 } & depth 2 & 3.5 & 3.5 & 3.4 & 3.5 & 3.5 \\
\cline { 2 - 7 } & depth 3 & 3.9 & 3.8 & 3.9 & 3.9 & 3.9 \\
\cline { 2 - 7 } & depth 4 & 3.6 & 3.6 & 3.7 & 3.6 & 3.6 \\
\cline { 2 - 7 } & pitch & 20 & 20.3 & 18.5 & 18.8 & 19.4 \\
\hline \multirow{5}{*}{8} & depth 1 & 4.4 & 4.5 & 4.5 & 4.5 & 4.5 \\
\cline { 2 - 7 } & depth 2 & 4.6 & 4.9 & 4.4 & 4.5 & 4.6 \\
\cline { 2 - 7 } & depth 3 & 5 & 5.1 & 4.5 & 4 & 4.7 \\
\cline { 2 - 7 } & depth 4 & 4.3 & 4.7 & 4.5 & 4.4 & 4.5 \\
\hline \multirow{4}{*}{9} & pitch & 20 & 20 & 19 & 19 & 19.5 \\
\cline { 2 - 7 } & depth 1 & 5.4 & 5.5 & 5.4 & 5.4 & 5.4 \\
\cline { 2 - 7 } & depth 2 & 4.8 & 5.1 & 5 & 5 & 5.0 \\
\cline { 2 - 7 } & depth 3 & 5.2 & 5.3 & 4.9 & 5.3 & 5.2 \\
\cline { 2 - 7 } & depth 4 & 5.5 & 5.3 & 5.1 & 5.3 & 5.3 \\
\hline
\end{tabular}

Four sets of different clearances or precision cutting widths were set when the water resistance experiment in table 4. Four samples of XLPE power cable meeting process requirement were preparated (corrugated aluminium sheath of optimized structure parameters). A sample of $3 \mathrm{~m}$ length was cut and in horizontal from no used cables. A ring of 50mm diameter that should contain all layers of materials except insulation shielding was cut off from the middle of cable. A tube of $20 \mathrm{~mm}$ diameter was placed on top of the ring vertically with a suitable device. The device and cable sheath surface which had been cut were sealed up together. The protrudent part of the seal should not be contacted by mechanical stress, certainly. The tube was injected into water of $20 \pm 10 \mathrm{C}$ about $5 \mathrm{~min}$ and the water column was $1 \mathrm{~m}$ higher than the center of the cable. Then samples were imposed 10 times heating cycles after $24 \mathrm{~h}$ placement. Conductor temperature was maintained in 95C $-100 \mathrm{C}$ but lower than $100 \mathrm{C}$ by heating conductor. The conductor should be maintained for at least $2 \mathrm{~h}$ at this temperature and cooled for at least $16 \mathrm{~h}$, naturally. In each heating period, water column also was kept $1 \mathrm{~m}$ invariably. The conductor temperature was measured on simulated cable as same as examined cable directly, by connecting simulated cable with examined cable in series.

\section{Test results}

\section{The effect of embossing depth and pitch on lateral pressure of corrugated aluminium sheath.}

Tensile strength and elongation of nine kinds of the sheaths(fifty-four samples) were measured with different embossing depths and pitchs by WDW-20 microcomputer control electronic universal testing machine, the results were showed in figure 1 and table 3. With the increasing ratio of embossed depth and pitch, longanimous pressure of the sheath was also increased. But corrugated aluminium sheath became deformed when the ratio was increased to more than a certain value of 0.2. Consequently, the pressure was no longer increased. The ratio of less than and close to 0.2 was obtained, which had best mechanical properties. So the fifth group of value was selected. As a result, maximum value of the yield-point stress was $2.26 \mathrm{KN}$ when embossing depth was $24.2 \mathrm{~mm}$ and pitch was $4.5 \mathrm{~mm}$ in the longanimous pressure range of the sheaths.

\section{The effect of different clearance on water resistance of power cable.}

In the water resistance experiment, insulated line group was manufactured with conductor wire core of $240 \mathrm{~mm}$ diameter first, and heated to $90 \mathrm{C}$. Then external diameters were measured by vernier caliper at the head end, tail end and the middle of insulated line group. Finally, the semi conductive buffer waterstop was winded on the insulated line group and the average external diameters were measured. 
Table 3 Prepared Parameters and Test Data of the Sheaths for Lateral Pressure

\begin{tabular}{|c|c|c|c|c|c|c|c|c|c|c|}
\hline \multirow{2}{*}{$\begin{array}{l}\text { Sample } \\
\text { No. }\end{array}$} & \multicolumn{2}{|l|}{$\begin{array}{l}\text { prepared } \\
\text { value }(\mathrm{mm})\end{array}$} & \multirow[b]{2}{*}{ ratio } & \multicolumn{2}{|c|}{$\begin{array}{l}\text { field } \\
\text { measurements }(\mathrm{mm})\end{array}$} & \multirow{2}{*}{$\begin{array}{l}\text { shrinkage } \\
\text { coefficient }\end{array}$} & \multicolumn{2}{|c|}{ Yield point } & \multicolumn{2}{|c|}{$\begin{array}{l}\text { Maximum } \\
\text { value }\end{array}$} \\
\hline & $\begin{array}{l}\text { embossed } \\
\text { depth }\end{array}$ & pitch & & $\begin{array}{l}\text { Pipe } \\
\text { length }\end{array}$ & $\begin{array}{l}\text { Embossed } \\
\text { depth }\end{array}$ & & $\begin{array}{l}\text { Pressure } \\
(\mathrm{KN})\end{array}$ & $\begin{array}{l}\text { Offset } \\
(\mathrm{mm})\end{array}$ & $\begin{array}{l}\text { Pressure } \\
(\mathrm{KN})\end{array}$ & $\begin{array}{l}\text { Offset } \\
(\mathrm{mm})\end{array}$ \\
\hline 1 & 4.1 & 30.8 & 0.133 & 1000 & 970 & 1.03 & 1.42 & 1.97 & 1.60 & 6.70 \\
\hline 2 & 4.5 & 30.5 & 0.148 & 1000 & 960 & 1.04 & 1.64 & 1.51 & 1.89 & 12.2 \\
\hline 3 & 5.5 & 30.3 & 0.182 & 1000 & 940 & 1.06 & 2.10 & 1.88 & 2.40 & 10.6 \\
\hline 4 & 3.8 & 23.9 & 0.159 & 1000 & 963 & 1.04 & 1.49 & 2.03 & 1.66 & 5.96 \\
\hline 5 & 23.9 & 4.7 & 0.197 & 1000 & 935 & 1.07 & 2.26 & 4.40 & 2.39 & 7.96 \\
\hline 6 & 5.4 & 23.7 & 0.228 & 1000 & 910 & 1.10 & 2.67 & 2.61 & 3.13 & 7.99 \\
\hline 7 & 3.6 & 19.4 & 0.186 & 1000 & 955 & 1.05 & 1.63 & 1.98 & 1.8 & 4.75 \\
\hline 8 & 4.6 & 19.5 & 0.236 & 1000 & 925 & 1.08 & 2.49 & 4.63 & 2.65 & 11.6 \\
\hline 9 & 5.2 & 19.2 & 0.271 & 1000 & 890 & 1.12 & 3.08 & 2.6 & 3.4 & 9.2 \\
\hline
\end{tabular}
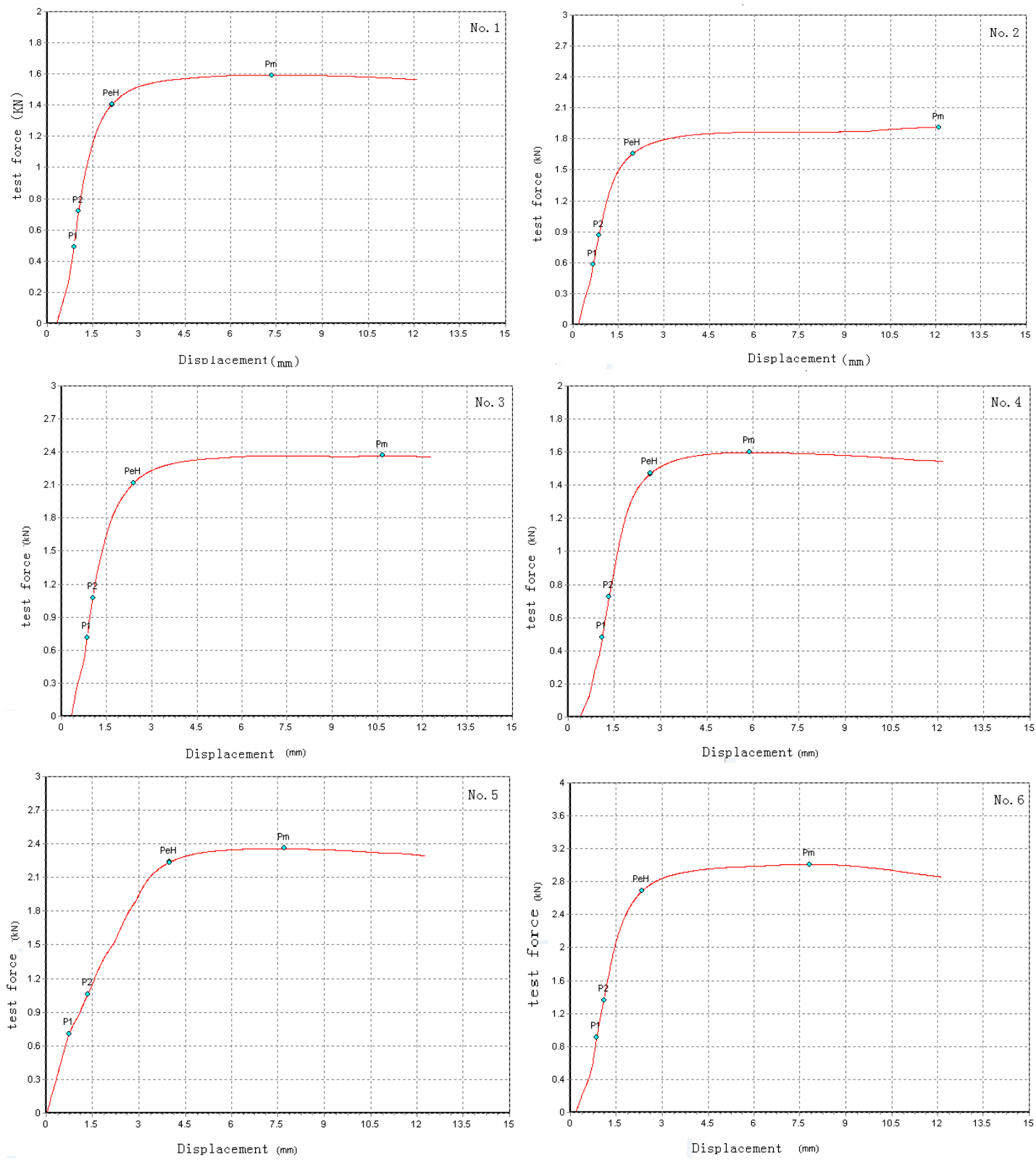

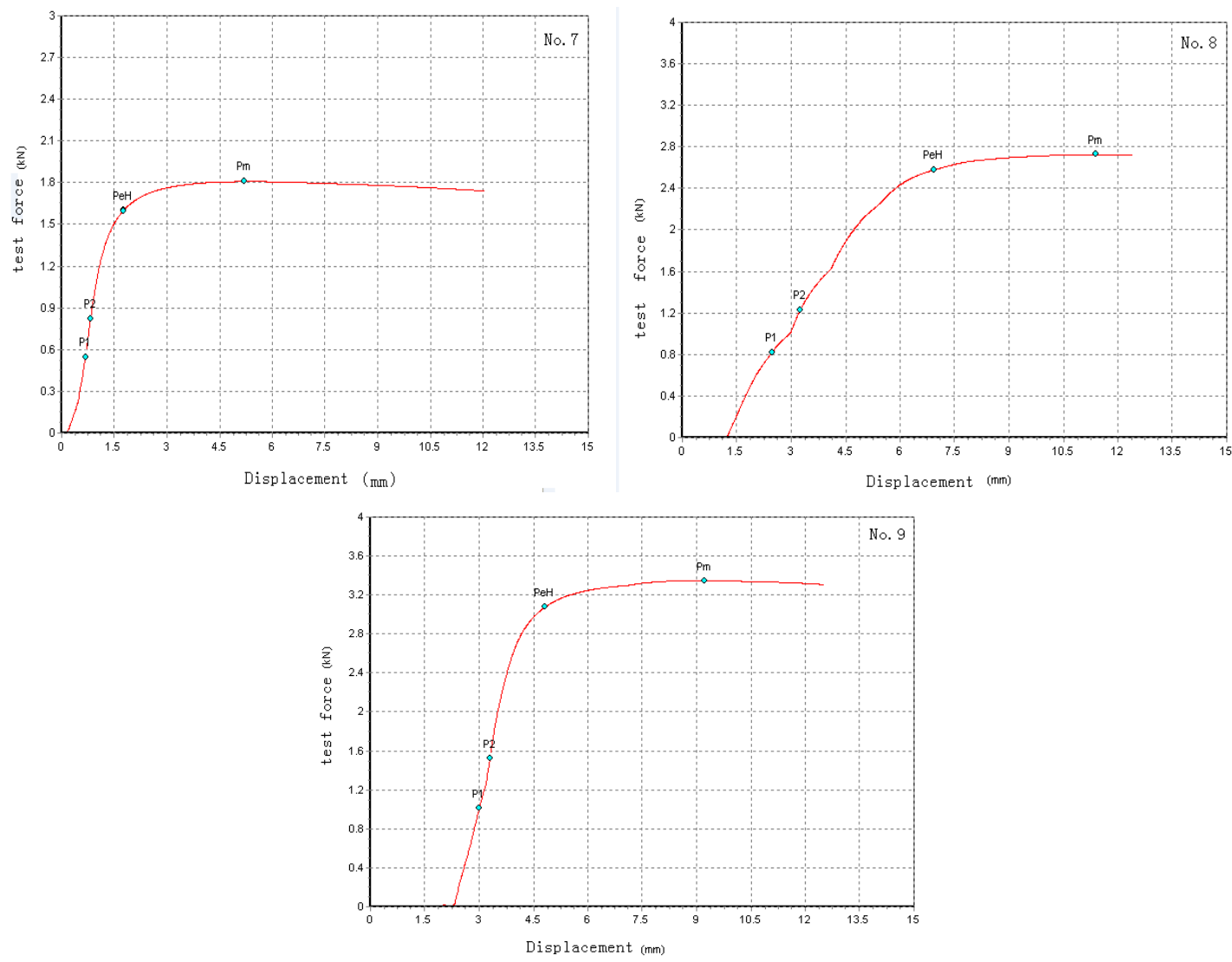

Figure1 Pressure -Displacement Curve

Dw was the average value of diameter, and was $66.7 \mathrm{~mm}$, the thickness of aluminium strip was $1.85 \mathrm{~mm}$.

$\mathrm{L}=\pi \mathrm{D}$

Where L was precision cutting width(Pipe girth), four groups of data from (1) were obtained: $244.7 \mathrm{~mm}, 247.9 \mathrm{~mm}, 251.1 \mathrm{~mm}, 254.3 \mathrm{~mm}$. Corrugated aluminium sheaths and four kinds of corresponding XLPE power cable samples were prepared according to aforesaid precision cutting widths. Water resistance experiment was made for four kinds of XLPE power cables to observe the situation of water seepage, respectively. The shorter of the length of water seepage, the better of water resistance performance, as shown in table 4. So the most appropriate precision cutting width of $244.7 \mathrm{~mm}$ and clearance of $-0.5 \mathrm{~mm}$ were selected.

The structure optimization parameters of corrugated aluminium sheath for water resistance were obtained from test results, which included embossing depth, pitch, clearance and precision cutting width, as shown in table 4.

Table4 Prepared Parameters of the Sheaths and Test Result for water resistance experiment

\begin{tabular}{|l|l|l|l|l|l|l|}
\hline & $\begin{array}{l}\text { Clearance } \\
\text { design }\end{array}$ & $\begin{array}{l}\text { wave crest diameter } \\
\text { of theory }\end{array}$ & $\begin{array}{l}\text { Pipe } \\
\text { diameter }\end{array}$ & $\begin{array}{l}\text { precision } \\
\text { cutting width } \\
\text { Design }\end{array}$ & $\begin{array}{l}\text { Water } \\
\text { penetration } \\
\text { length }\end{array}$ & unit \\
\cline { 2 - 7 } $\begin{array}{l}\text { Test } \\
\text { samples }\end{array}$ & -0.5 & 78.4 & 79.8 & 244.7 & 0.31 & $\mathrm{~mm}$ \\
\cline { 2 - 7 } & 0 & 79.4 & 80.8 & 247.9 & 0.55 & $\mathrm{~mm}$ \\
\cline { 2 - 7 } & 0.5 & 80.4 & 81.8 & 251.1 & 0.87 & $\mathrm{~mm}$ \\
\cline { 2 - 6 } & 1 & 81.4 & 82.8 & 254.3 & 1.89 & $\mathrm{~mm}$ \\
\hline
\end{tabular}

\section{Conclusion}

The corrugated aluminium sheath structure optimization parameters were gotten through the study on mechanical properties of nine kinds of different structure of corrugated aluminium sheaths. Maximum value of the yield-point stress was $2.26 \mathrm{KN}$ when embossing depth was $24.2 \mathrm{~mm}$ 
and pitch was $4.5 \mathrm{~mm}$ in the longanimous pressure range of the sheaths. Four sets of different clearances or precision cutting widths of XLPE power cables were set in the water resistance experiment, the most appropriate precision cutting width of $244.7 \mathrm{~mm}$ and clearance of $-0.5 \mathrm{~mm}$ were selected. Longitudinal water resistance performance of XLPE power cable was improved, which based on the experimental optimization of XLPE power cable corrugated aluminium sheath structure with the best mechanical properties.

\section{Acknowledgement}

In this paper, the research was sponsored by the Nature Science Foundation of Heilongiang Province of China under Grant Nos. (Project No. E201130)

\section{References}

[1].J. Wu.Study of the mechanism of bow-tie water trees initiation in XLPE power cables[J].Journal of Xi'An JiaoTong University, 1987. 21（04）: 65-72

[2].D. C. Zheng, R. X. Yang, Z. L. Zhang, W. L. Wang. Mathematical analysis of discharge process in the short air-gap with dielectric-covered electrodes[J].Journal of Harbin University of Science and Technology, 2012.17(03): 14-18

[3].P. H. Zhang, T. Shan, Y. J. Shi, Y. L. Qi, X. H. Du. Parametric design of insulation structure and analysis of the electric field at winding end of transformer[J].Journal of Harbin University of Science and Technology, 2012.17 ( 02 2) : 76-79

[4].Z. J. Liu, J. Chang, P. Fang. The water blocking technology in electrical power cable[J].Electric Wire \& Cable, 2013. (01) : 12-14, 20

[5].F. Z. Wang, J. Yang. Characteristics of the manufacturing process for metallic sheathing on HV/EHV XLPE insulated cables[J].Electric Wire \& Cable, 2010. （05） : 8-10

[6].X. H. Wang, Z. Q. Mei, X. D. Zhang, L. H. Zhang. Water blocking cable," [J]. China patent, CN200720045736. 6, 2008

[7].X. Zhang. A new type of water blocking yarn for electrical wire \& cable and optical fiber cable[J]. Electric Wire \& Cable, 2008. (01) : 36-37,

[8]T. Li, R. Chen. Investigation of the water-blocking mechanism and construction of water-blocked MV/HV XLPE cables[J]. Electric Wire \& Cable, 2008.（02） : 37-37,44

[9].J. M. Chen, J. P. Liu, J. G. Zeng. Study on the test technique for longitudinal watertightness of electric cables[J].Electric Wire \& Cable, 2005. (03) : 27-29

[10].Y. Z. Yang, H. Y. Tian. Main constructions and key processes for water-blocking power cables[J].Electric Wire \& Cable, 2003. (01) : 13-16, 19 